\title{
Motor Innervation of Dorsoventrally Reversed Wings in Chick/Quail Chimeric Embryos
}

\author{
Michael J. Ferns ${ }^{a}$ and Margaret Hollyday \\ Department of Biology, Bryn Mawr College, Bryn Mawr, Pennsylvania 19010
}

In the limb plexus, motor axons destined for limb muscles diverge along separate pathways to innervate muscles derived from either the dorsal or ventral premuscle masses. We have examined the axonal guidance cues involved in this initial, specific pathway choice at the plexus by making dorsoventral $(D / V)$ limb bud reversals prior to innervation. Chick/quail chimeras were used to determine the proximodistal level of the reversal in tissue sections. The specificity of the projections to dorsal or ventral nerve trunks was assessed by retrograde HRP labeling at ages prior to motoneuron death. Axons corrected for the reversal when the level of the graft was proximal to the plexus, and when the reversed limb and its gross nerve pattern were normal. If all of these conditions were not satisfied, aberrant innervation patterns were observed. Axonal trajectories were analyzed within the host tissue, at the host-graft border, and within rotated tissue to determine where along the pathway guidance cues might be located. Special attention was given to cases in which axons compensated for the reversal to project in accord with the positions of their soma in the lateral motor column. In these correcting cases, after normal D/V sorting in the spinal nerves of the host, motor axons altered their trajectories upon entering rotated graft tissue as they approached and traversed the plexus. Because corrections were within rotated tissue and not proximal to it, the D/V pathway cues are unlikely to be long-range target-derived signals, but rather appear to be closely associated with positional information in the plexus region and also more proximally in the tissue surrounding the distal spinal nerves.

[Key words: axonal guidance, chick embryo, limb bud, motoneurons, neuronal specificity, positional information]

Specific and nonspecific growth cues operate as guidance mechanisms in the developing chick wing. The gross nerve pattern is apparently shaped by nonspecific guidance factors, but the trajectories of individual axons rely on more specific cues. We have focused on the brachial plexus as the site of a decision region between dorsal and ventral pathways.

In the chicken, as in other vertebrates, motoneurons innervating a specific limb muscle form a motor pool located in a characteristic position within the lateral motor column (LMC)

Received Aug. 19, 1992; revised Dec. 4, 1992; accepted Dec. 9, 1992.

This research was supported by NIH RO1 NS 25340. We thank Melissa Peters for help in preparing the figures, and Megan Morgan-Carr and Jeff Carr for comments on the manuscript.

Correspondence should be addressed to Margarct Hollyday at the above address.

-Present address: Department of Physiology, University of California Medical School, San Francisco, CA 94143.

Copyright (C) 1993 Society for Neuroscience $0270-6474 / 93 / 132463-14 \$ 05.00 / 0$ of the spinal cord. The position of the respective motor pools is correlated with the embryonic origin of the muscles they innervate. Limb musculature is derived from two premuscle masses, lying dorsally and ventrally, which successively cleave to form the individual muscles. Muscles derived from the dorsal muscle mass are innervated by motoneurons positioned laterally within the $\mathrm{LMC}$, and ventrally derived muscles are supplied by medially positioned motoncurons (Landmesser, 1978a; Hollyday, 1980; Hollyday and Jacobson, 1990). This relationship is preserved even in experimental situations where the innervation is forcign, or inappropriate along the anterior/posterior $(\mathrm{A} / \mathrm{P})$ axis (Morris, 1978; Hollyday, 1981; Lance-Jones and Landmesser, 1981b; Straznicky, 1983; Whitelaw and Hollyday, 1983b).

Developmentally, this pattern forms by specific axonal growth at early stages of limb innervation. The outgrowing lateral and medial motoneuron axons traverse common pathways in the spinal nerves until they reach the plexus region, where they converge and intermingle, subsequently diverging as peripheral nerves to project selectively to the dorsal and ventral musculature, respectively (Landmesser, 1978b). Correct dorsoventral (D/V) pathway selection has been shown to occur in limbs devoid of muscle cells (Phelan and Hollyday, 1990), and at least to some degree following limb bud removal (Tosney and Landmesser, 1984), and Lance-Jones (1986) found that normal axon sorting occurred in the distal spinal nerves of embryos with a double complement of dorsally derived musculature. Those results indicate that the $\mathrm{D} / \mathrm{V}$ guidance cues are probably not target derived, but are more likely associated with the pathways leading to those targets.

In theory, the guidance mechanisms involved can be active, where lateral and medial motoneurons respond selectively to specific guidance cues, or passive, where axons are deployed according to nonspecific growth cues. A number of previous studies have tested the character of the mechanism by which motoneurons are guided to their dorsal and ventral targets by rotating limb buds of chick embryos about the $\mathrm{D} / \mathrm{V}$ axis prior to innervation. These experiments have produced conflicting results. Ferguson (1983) and Laing (1984) reported correct innervation of $\mathrm{D} / \mathrm{V}$-rotated hindlimbs and wings, respectively, with the motoneurons actively compensating for the reversal and projecting appropriately to the respective muscle masses. In contrast, Summerbell and Stirling (1981; Stirling and Summerbell, 1985) found no evidence of selectivity in the motor projections, with the motor axons apparently being passively channeled to the inappropriate (reversed) musculature. Similarly, incorrect innervation was found after $\mathrm{D} / \mathrm{V}$ rotations of distal limb segments (Whitelaw and Hollyday, 1983c).

One of the difficulties in interpreting the previous studies was 

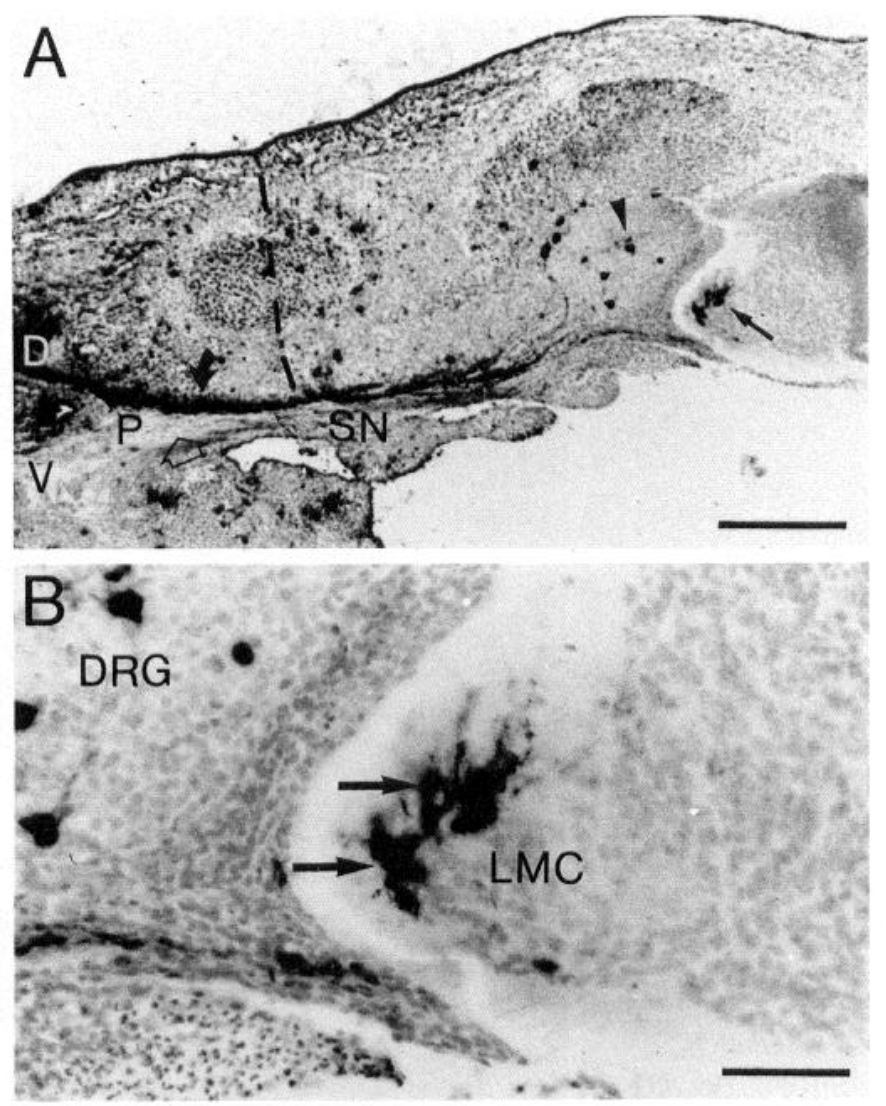

Figure 1. Control chimeric embryo (stage 29) with a quail wing grafted in normal $\mathrm{D} / \mathrm{V}$ orientation. $A, \mathrm{HRP}$ was injected into the dorsal radial nerve (to the left, out of the field of view). Retrogradely labeled axons (curved solid arrow), and sensory (solid arrowhead) and motor (straight solid arrow) neurons are visible. Note that the labeled axons segregate to a dorsal position in the spinal nerve $(S N)$, proximal to the plexus $(P)$, where dorsal $(D)$ and ventral $(V)$ pathways diverge. Unlabeled axons in the distal spinal nerve just proximal to the plexus are marked with an open arrow. The host-graft border (broken line) is proximal to the plexus, and was drawn while examining the section at a greater magnification. $B$, Higher magnification of the lateral motor column $(L M C)$, indicating that the motoneurons retrogradely labeled by the dorsal injection are in the appropriate lateral position (arrows). Some labeled sensory neurons are present in the adjacent dorsal root ganglion $(D R G)$. Scale bars: $A, 200 \mu \mathrm{m} ; B, 50 \mu \mathrm{m}$.

that the boundary between unrotated host tissue and rotated donor tissue could not be determined. We thought that the conflicting results might reflect either variations among the previous studies in the proximodistal (P/D) level of the $\mathrm{D} / \mathrm{V}$ reversals, or unrecognized abnormalities in the rotated limb buds. Therefore, we made $\mathrm{D} / \mathrm{V}$ limb bud reversals at a proximal level using chick/quail chimeras. The use of chimeras allowed us to determine the level of the reversal; it also permitted characterization of the morphology of the limb buds and nerve plexuses adjacent to the host-graft border. Additionally, we were able to examine axon trajectories in relation to the point of reversal, to characterize further the distribution and form of the specific guidance cues governing the $\mathrm{D} / \mathrm{V}$ pathway choice.

Portions of this work have been previously published in abstract form (Ferns and Hollyday, 1989).

\section{Materials and Methods}

Experiments were performed using White Leghorn chick and Japanese quail eggs, incubated in a forced draft incubator at $38.5^{\circ} \mathrm{C}$. Both chick and quail embryos were staged according to the series of Hamburger and Hamilton (1951).

Surgery. The limb bud reversal operations were performed on day 3 of incubation, between chick and quail embryos within stage 18 , whose limb buds were similar in terms of development. At this stage the somitically derived muscle precursor cells have migrated into the limb bud (Jacob et al., 1978), but limb innervation has not yet occurred. At the time of the surgery, a few motor axons have begun to collect at the end of the myotome, but they do not normally reach the limb base until stage 22 (Hollyday, 1983), more than a day after the surgery was performed. Thus, it is unlikely that any motor axons were cut at the time of wing reversal.

The host chick embryos were prepared for in ovo surgery by sanding a window in the egg to provide access, and by staining the membranes and embryo with agar impregnated with neutral red to aid visualization. The right wing bud was surgically removed with electrolytically sharpened tungsten needles, creating a pocket into which the dissected donor quail wing bud was introduced. The graft was either a direct replacement with the right quail wing bud to give normally oriented controls, or a replacement with the left quail wing bud to give normal $\mathrm{A} / \mathrm{P}$ but $180^{\circ}$ D/V-reversed experimental wings. We attempted to make all grafts immediately adjacent to the somites, as far proximal to the plexus as was possible, because our primary interest was to study situations in which axons had the opportunity to compensate for the rotation within the plexus region. Nevertheless, we observed variation in the resulting proximodistal level of the incorporated graft, which presumably arose in the process of fusion of the graft to host. This variability was particularly evident in the D/V-reversed cases (see Results). After surgery the eggs were resealed with a glass coverslip and paraffin, and returned to the incubator.

HRP labeling. The specificity of the innervation of donor wings was assessed after a further $3 \mathrm{~d}$ of incubation, at day 6 (stage 28-29), by retrograde HRP labeling following injections into specific nerve trunks within the wing. The characteristic pattern of nerve branches is established in the upper limb regions at this time (Hollyday, 1983). Because the vast majority of naturally occurring motoneuron death occurs at later stages (Oppenheim and Majors-Willard, 1978), the observed axonal projections reflected the pattern of initial axon outgrowth.

HRP injections were made using the in vitro technique described by Landmesser (1978a). Embryos were removed from the egg to a Sylgardlined plastic dish containing warm, oxygenated Tyrode's solution. They were perfused with the above solution and eviscerated, and a ventral laminectomy was performed to expose the brachial spinal cord. Pressure injections of a solution of HRP (approximately $20 \%$ dissolved in Tyrode's) were then made using a fine glass micropipette. Specific injections were made directly into either the dorsal radialis or ventral brachialis inferior nerve trunks in the donor limbs, and additionally in some cases into the equivalent nerve in the control or left chick wing.

The embryo was incubated at room temperature for $4-5 \mathrm{hr}$ for retrograde transport of the injected HRP, and then fixed in Helly's fixative for 4-6 hr, washed, and processed for paraffin histology. Generally, the embryos were serially sectioned in transverse orientation at $8 \mu \mathrm{m}$, through the entire brachial region. In some cases the wings were separated from the spinal cords and sectioned sagittally. The serial sections were mounted on slides and stained by the Feulgen method (Le Douarin, 1973) to allow identification of chick and quail tissue by their characteristic nucleolar staining.

HRP labeling was demonstrated immunohistochemically in the paraffin sections with the peroxidase-antiperoxidase method (Sternberger, 1979). An anti-HRP antibody (rabbit, 1:1500; Sigma) was used to detect the transported HRP, and then combined via a linking antibody (goat anti-rabbit, 1:100; Sigma) to a peroxidase-antiperoxidase complex (rabbit, 1:200; Sigma). Diaminobenzidine was used as the substrate for the chromogenic reaction.

Analysis. All cases were carefully examined to assess qualitatively the correctness of motor innervation based on the well-established relationship between medial or lateral position of motoneurons in the LMC and innervation of ventral or dorsal muscle mass, respectively. A further detailed quantitative analysis was made of all dorsoventrally reversed wings showing correct innervation, and of selected cases showing aberrant innervation; a representative set of normal orientation chimeric embryos were also analyzed. In these cases, camera lucida drawings were made at a magnification of $110 \times$, of every fifth section through the brachial region of the experimental embryos, detailing the spinal cord and general features of the limb, in particular the position of the host-graft border and the trajectories of the retrogradely labeled axons 

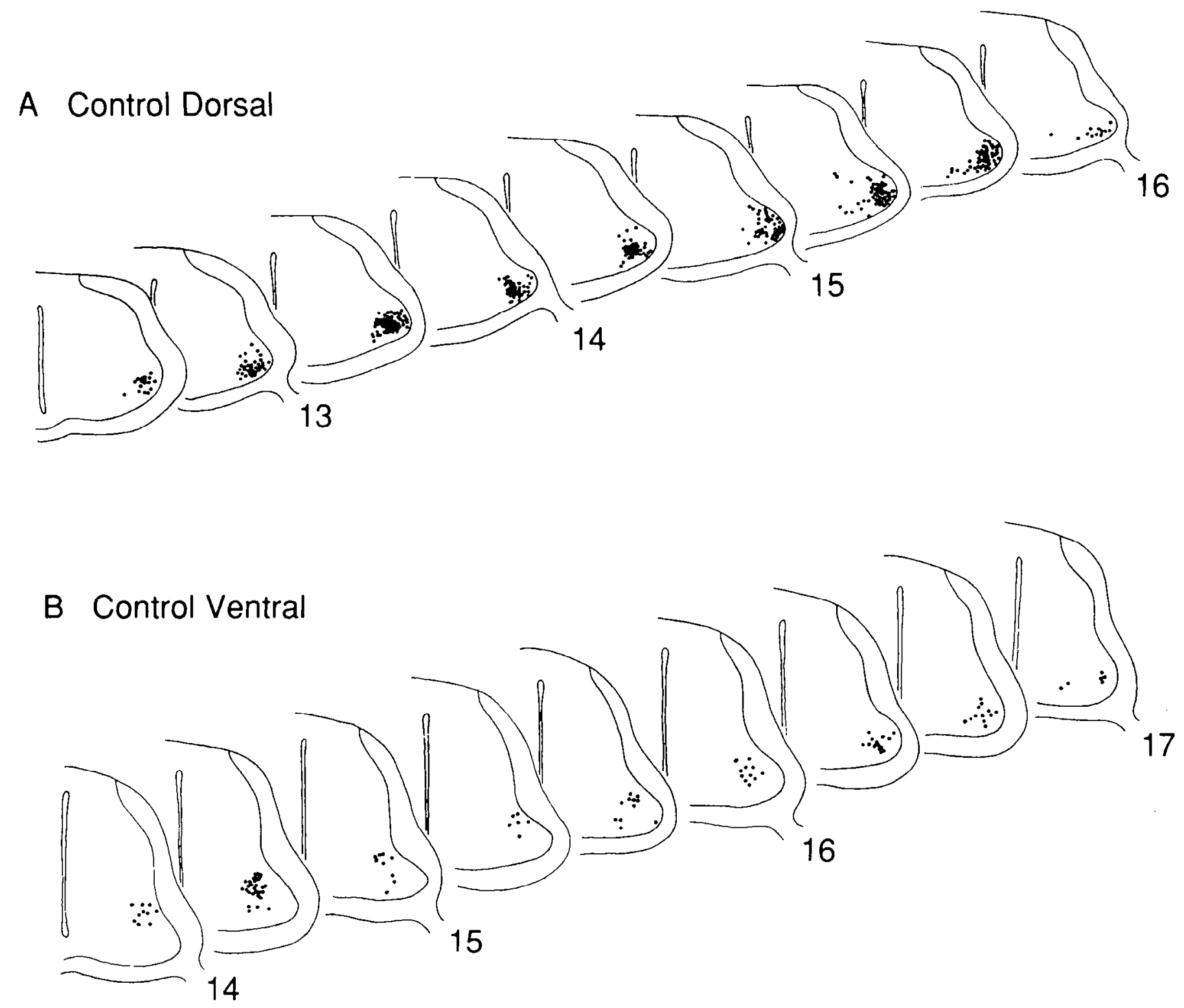

Figure 2. Reconstructions of spinal cord sections showing positions of retrogradely labeled motoneurons following dorsal $(A)$ and ventral $(B)$ nerve trunk injections in chimeras with wings grafted in normal orientation. $A$, Motoneurons retrogradely labeled by a dorsal, radial nerve injection predominantly lie in the appropriate lateral position in the transverse plane of the LMC (data from same chimera shown in Fig. 1). $B$, Motoneurons labeled by a ventral brachialis inferior nerve injection were also appropriate, lying medially in the LMC. Numbers identify the ventral roots of each spinal cord segment.

within the spinal nerves, plexus, and peripheral nerve trunks. In addition, the numbers and positions of the retrogradely labeled motoneurons within the transverse plane of the LMC were determined for every section, and marked on camera lucida drawings, at a magnification of $185 \times$. Five sections were combined for each drawing in the composite reconstructions to summarize the mediolateral distribution, or degree of appropriateness, of the labeled motoneurons. Histograms were also constructed showing the rostrocaudal distribution of medially and laterally positioned labeled motoneurons.

\section{Results}

Surgery was performed on over 300 embryos. Normal-orientation control operations generally resulted in essentially normal, well-innervated donor limbs. D/V reversal operations, however, frequently produced limbs that were uninnervated or had received severely depleted innervation. This was usually due to unsuitable positioning of the limb, or to skeletal abnor- malities in the shoulder region, both of which blocked entry of the chick spinal nerves. Such embryos were not studied further. A total of 45 embryos proved suitable for analysis, having wellinnervated donor limbs, and additionally, having successful and specific peripheral nerve HRP injections with good retrograde labeling.

\section{Quail wings grafted in control (unrotated) orientation}

Twenty-four chimeras with wings grafted in normal orientation were analyzed. These grafted wings showed spontaneous movements, were supplied by the normal (chick) brachial spinal cord segments (13-16), and had a grossly normal pattern of innervation. To assess the specificity of innervation, HRP injections were made either into the radialis nerve $(N=14)$, a common nerve trunk supplying several dorsally derived muscles of the distal wing, or into the brachialis inferior nerve $(N=10)$, a 

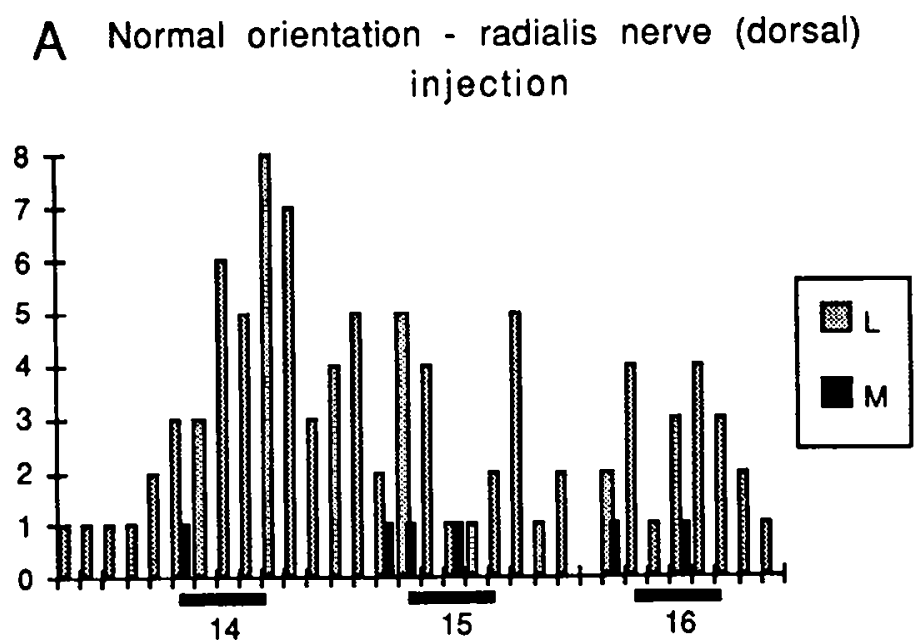

C D/V reversed orientation - radialis nerve (dorsal) injection

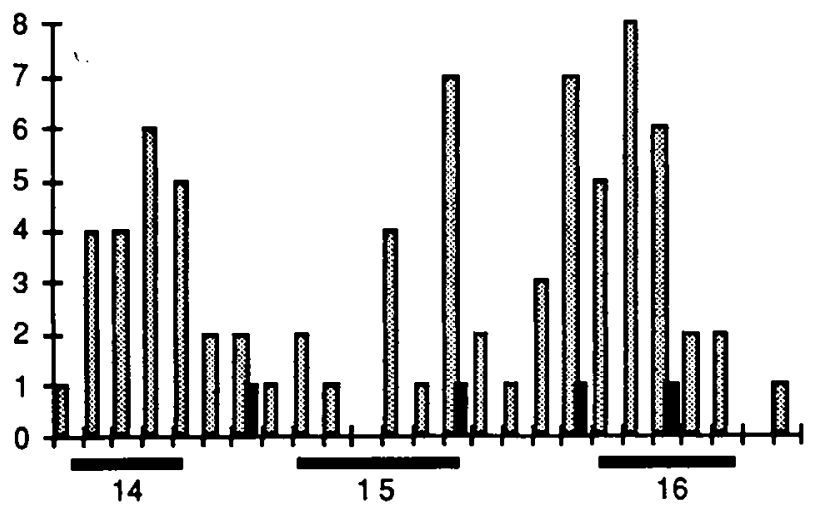

\section{E D/V reversed orientation - radialis nerve} (dorsal) injection

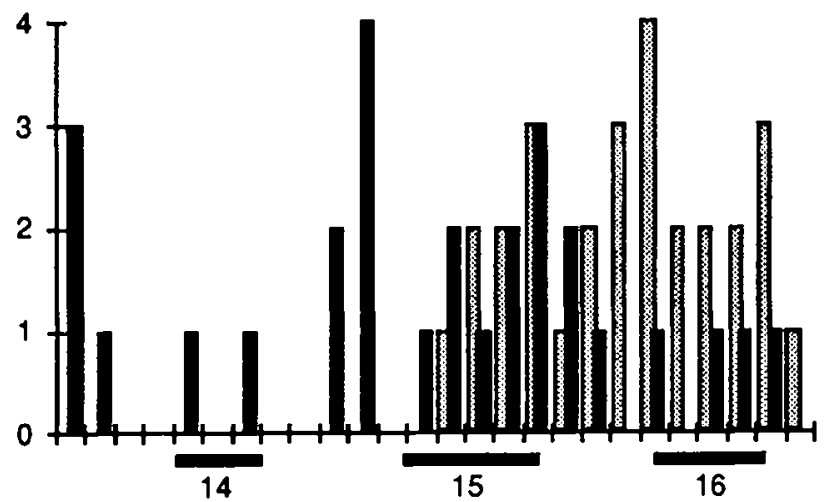

B Normal orientation - brachialis inferior (ventral) injection

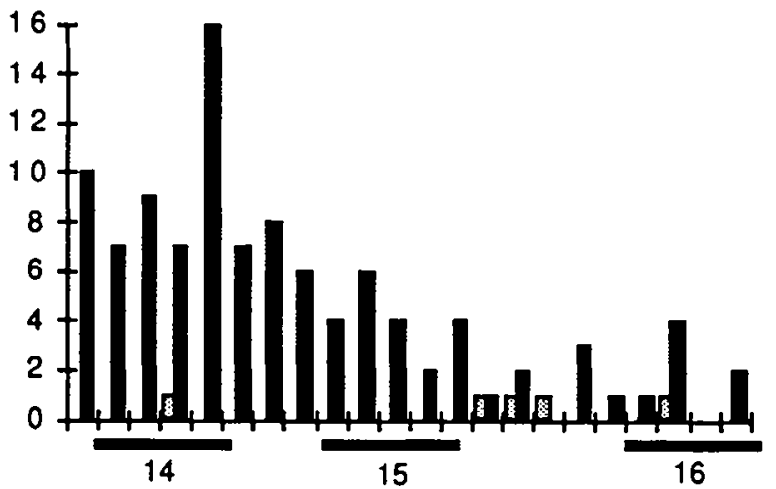

D D/V reversed orientation - brachialis nerve (ventral) injection

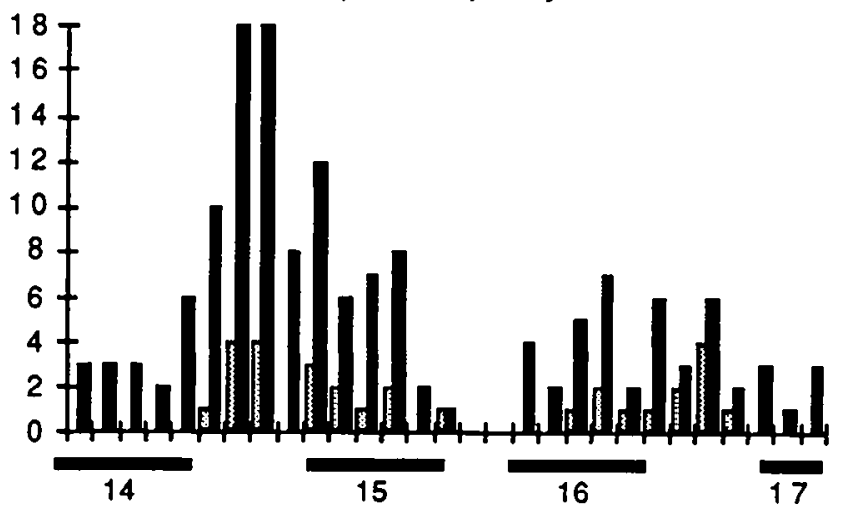

F D/V reversed orientation - brachialis inferior (ventral) nerve injection

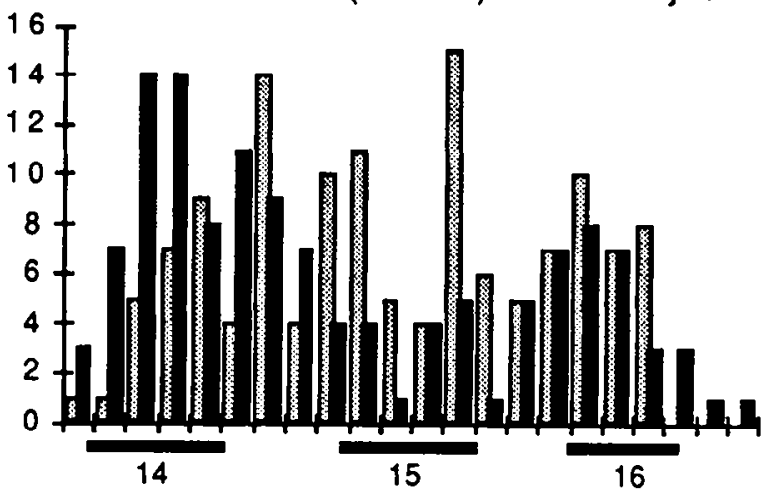

Figure 3. Histograms showing distribution of laterally positioned and medially positioned labeled motoneurons along the rostrocaudal axis of the LMC. $A$ and $B$, Control embryos with normally oriented grafted wings. $C$ and $D$, Experimental embryos with D/V-rotated wings in which essentially correct innervation patterns were observed. $E$ and $F$, Experimental embryos with $\mathrm{D} / \mathrm{V}$-rotated wings innervated by a mixture of appropriate and inappropriate motoneurons. HRP was injected into the radialis nerve, which innervates dorsally derived muscles in the cases shown in $A$, $C$, and $E$; the brachialis inferior projecting to ventrally derived muscles was injected in the cases shown in $B, D$, and $F$. Labeled motoneurons positioned laterally $(L)$ within the LMC are shown in cross-hatching. Medially $(M)$ positioned motoneurons are shown by solid bars. Numbers of labeled motoneurons are shown on the ordinate. Solid bars beneath the abscissa show the positions of the identified ventral roots. 
common nerve trunk innervating ventrally derived muscles of the wing. In all cases, the retrogradely labeled motoneurons were appropriately positioned in the LMC for the peripheral nerve injected. Labcled motoneurons were located predominantly laterally within the transverse plane of the LMC for dorsal nerve trunk injections (Figs. 1, 2A), and medially for ventral nerve trunk injections (Fig. $2 B$ ). Histograms showing the rostrocaudal distribution of both laterally and medially positioned labeled motoneurons in two representative control cases are shown in Figure 3, $A$ and $B$. Note that a small percentage of the labeled motoneurons are aberrantly positioned, even in normally oriented controls (see also Table 1).

In both control and experimental embryos, the host-graft border was easy to define when the sections were examined, as relatively little mixing between chick and quail cells occurred. At lower magnifications, quail cells appeared more darkly stained by the Feulgen reaction than did chick cells due to differences in the staining of their nuclei (Figs. 1, $4 A-D$ ). When examined at higher magnifications (Fig. $4 E, F$ ), it was easy to identify quail cells whose nuclei had regions of darkly staining heterochromatin. These nuclei were clearly distinct from the more palely staining cuchromatic nucleoli of the chicken cells.

In normal-orientation controls, the level of the graft did not vary significantly and was always found to be proximal to the plexus region, which we define as the volume of tissue encompassing the point of convergence of the spinal nerves to the point of divergence of the dorsal and ventral nerve trunks (Fig. $1 A)$. In addition, plexus location, ccll differentiation, and pattern formation in the shoulder region of the chimera were all essentially normal. The trajectories of the retrogradely labeled axons indicated that after exiting the ventral roots in relatively mixed fashion, the axons segregated to dorsal and ventral positions within the spinal nerves, proximal to the plexus and the hostgraft border (Fig. 1 $A$ ). The axons of lateral and medial motoneurons then diverged in the plexus within the donor quail tissue to project to dorsal and ventral pathways. Chick motoneurons, therefore, appear able to respond selectively to guidance cues in the quail tissue, and project appropriately on the D/V axis to the unrotated quail limb.

\section{Quail wings grafted in $D / V$-reversed orientation}

Twenty-one chimeras with wings grafted in $180^{\circ} \mathrm{D} / \mathrm{V}$-reversed orientation were analyzed, and had innervation patterns falling into two general classes, either largely correct, or aberrant (consisting of varying mixtures of correct and incorrect motor innervation). Cases in which $80 \%$ or more of the labeled motoneurons were in the appropriate medial or lateral part of the LMC were classified as correct. Cases in which fewer than $80 \%$ of the labeled motoneurons were located in the expected half of the LMC were classified as having abcrrant innervation patterns.

Correct innervation patterns. Eight chimeras showed evidence of selective motor innervation of the reversed wings, with greater than $80 \%$ of the labeled motoneurons being positioned appropriately in the LMC for the peripheral nerve injected (Table 1). In each of these cases, the level of rotation was proximal to the plexus region, the girdle elements of the graft (scapula and coracoid) were fused with chick girdle (scapula), and the morphology of the reversed limb and nerve patterns was largely normal in the shoulder region (Table 2).

Injections of HRP made into the dorsal radialis nerve $(N=$ $5)$, although now positioned ventrally with respect to the host
Table 1. Mediolateral positioning of labeled motoneurons following nerve trunk injections in grafted wings

No. labeled motoneurons

\begin{tabular}{|c|c|c|c|c|c|}
\hline \multirow[b]{2}{*}{$\begin{array}{l}\text { Nerve } \\
\text { injected }\end{array}$} & \multirow[b]{2}{*}{ Case } & \\
\hline & & $\mathbf{L}$ & $\mathbf{M}$ & Total & $\begin{array}{l}\% \\
\text { Incorrect }\end{array}$ \\
\hline \multicolumn{6}{|c|}{ Normal orientation } \\
\hline \multirow[t]{2}{*}{ Dorsal } & 92 & 384 & 12 & 396 & 3.0 \\
\hline & 145 & 93 & 6 & 99 & 6.1 \\
\hline \multirow[t]{2}{*}{ Ventral } & 186 & 5 & 104 & 109 & 4.6 \\
\hline & 251 & 7 & 104 & 111 & 6.3 \\
\hline \multicolumn{6}{|c|}{$\mathrm{D} / \mathrm{V}$-reversed orientation } \\
\hline \multirow[t]{5}{*}{ Dorsal } & 27 & 77 & 4 & 81 & 4.9 \\
\hline & 135 & 53 & 3 & 56 & 5.4 \\
\hline & 137 & 44 & 5 & 49 & 10.2 \\
\hline & 162 & 31 & 5 & 36 & 13.9 \\
\hline & 167 & 29 & 4 & 33 & 12.1 \\
\hline \multirow[t]{3}{*}{ Ventral } & 203 & 30 & 151 & 181 & 16.6 \\
\hline & 208 & 4 & 43 & 46 & 8.7 \\
\hline & 238 & 14 & 59 & 73 & 19.2 \\
\hline
\end{tabular}

L, laterally positioned; M, medially positioned; \% Incorrect, percentage of incorrectly positioned motoneurons.

axes (sce, e.g., Fig. $4 A$ ), labeled motoneurons predominantly in a lateral position in the LMC (Figs. $4 B, 5 A$ ). The rostrocaudal distribution of both laterally (correctly positioned) and medially positioncd (aberrantly positioned) labeled motoncurons for a case in which the radialis nerve was injected is shown in Figure $3 C$. I abeled motoneurons were widely distributed along the rostrocaudal axis of the $\mathrm{LMC}$, as was observed in normal orientation control experiments (c.g., Fig. 3A).

Injections were also made into nerves supplying ventrally derived muscles $(N=3)$. In two embryos with $\mathrm{D} / \mathrm{V}$-rotated wings, injections were made into the brachialis inferior nerve trunk. In these cases, labcled motoneurons were in general appropriatcly located medially within the LMC and widely distributed along the rostrocaudal axis (Fig. 3D), as was observed in normal embryos. In one additional chimera, fortuitously only the biceps muscle nerve was injected (Fig. 6.), rather than the entire brachialis inferior nerve trunk. The motoneurons labeled by this injection were positioned far medially in the $\mathrm{LMC}$, in segments 14 and 15 (Figs. $5 B, 6 B$ ). This is the normal position of the biceps motor pool (Ohmori ct al., 1982; Straznicky and Tay, 1983; Hollyday and Jacobson, 1990). In these cases, therefore, the outgrowing axons had compensated for the reversal and projected selectively to the correct dorsally or ventrally derived musculature, and probably also to their correct muscle.

We analyzed the positions of labeled axons in serial sections from the injection sites to the spinal nerves in order to determine where the correction occurred in relation to the reversal. Because we studied the embryos at stages shortly after the wing innervation first forms and prior to cell death, we also assume that the relative positions of labeled axons reflect their trajectories during initial outgrowth. If axons altered their trajectories after entering rotated quail tissue, such observations would suggest that contact-mediated cues govern the $\mathrm{D} / \mathrm{V}$ pathway decision. Alternatively, if axons abruptly changed their trajectories clearly proximal to the quail cells, this observation would suggest that the $D / V$ pathway decision involved signaling at some distance. This would provide information on both the form and distri- 

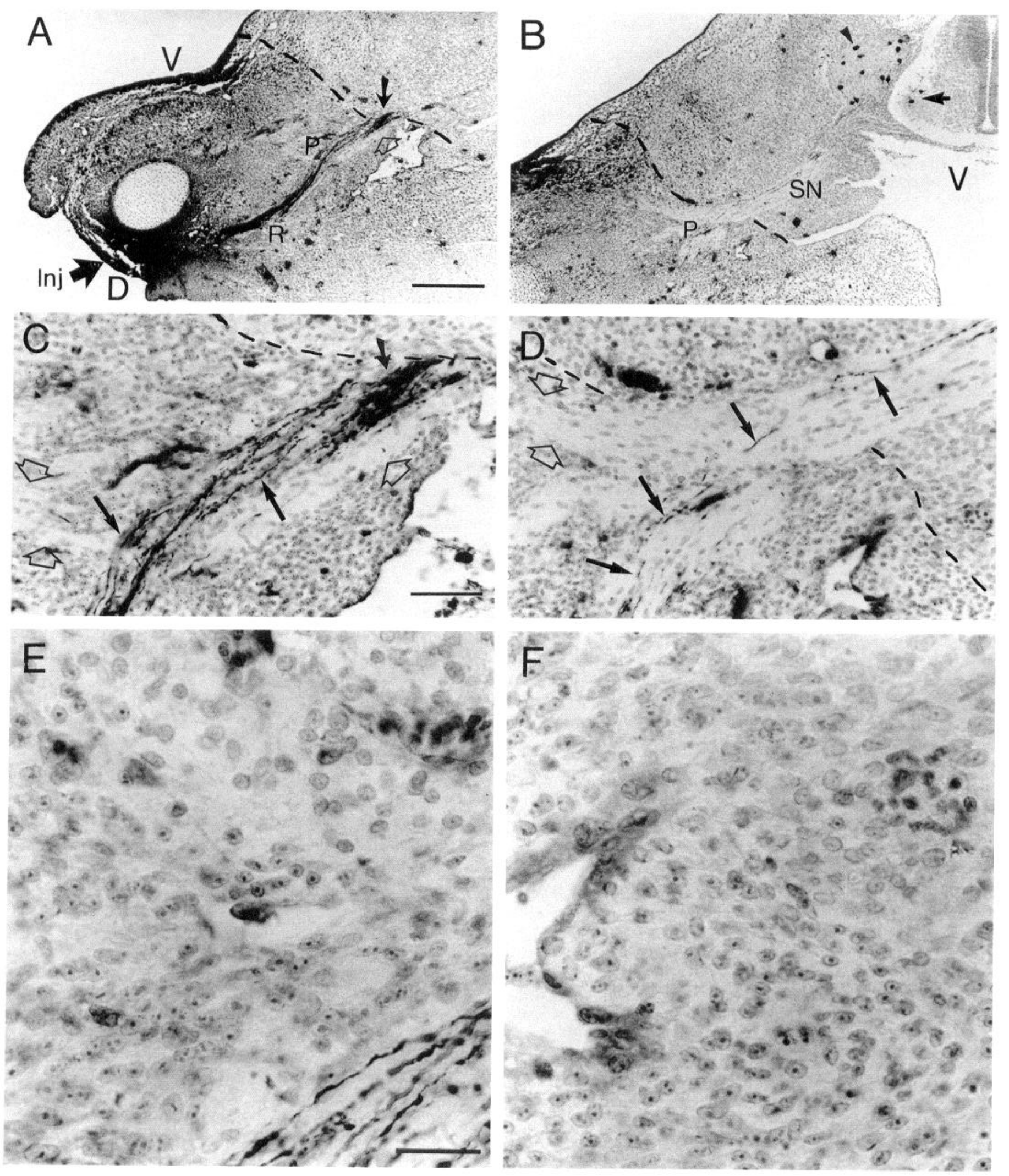

Figure 4. Experimental chimera (stage 28 embryo) with a quail wing grafted in D/V-reversed orientation (dorsal nerve trunk injection). Broken lines in $A-D$ mark the border between unrotated chick and rotated quail tissue; the border is shown at higher magnification in $E$ and $F$. $A$, Transverse sections showing injection site $(I n j)$ and retrogradely labeled axons in the radial nerve $(R)$ and plexus $(P)$. Note that proximal to the plexus, in the spinal nerve, the labeled axons (curved arrow) are positioned dorsally to unstained ventral axons (open arrow). $D$ and $V$ denote the reversed orientation of the grafted limb relative to the body axes of the host. $B$, A more rostral section through the embryo showing lateral position of HRP labeled neurons in LMC (arrow). Sensory neurons in the DRG were also labeled (arrowhead). A few labeled axons within the spinal nerve $(S N)$ are also visible (see $D$ ). At this level, the host-graft border is just proximal to the plexus region $(P)$. $V$ denotes the ventral side of the spinal cord 
Table 2. Degree of correct innervation of rotated wing, and its relationship to limb bud differentiation and peripheral nerve pattern formation

\begin{tabular}{|c|c|c|c|c|c|c|c|}
\hline Case & $\begin{array}{l}\text { Inner- } \\
\text { vation }\end{array}$ & Level & Girdle & $\begin{array}{l}\text { Limb } \\
\text { position }\end{array}$ & $\begin{array}{l}\text { Limb } \\
\text { differentiation }\end{array}$ & $\begin{array}{l}\text { Plexus } \\
\text { location }\end{array}$ & Nerve pattern \\
\hline CQ27 & $\mathrm{C}$ & $\operatorname{Pr}$ & fused & aligned & normal & normal & normal \\
\hline CQ135 & $\mathrm{C}$ & $\operatorname{Pr}$ & cor $a b$ & oblique & normal & normal & normal (ex Pec) \\
\hline CQ137 & $\mathrm{C}$ & $\operatorname{Pr}$ & fused & aligned & normal & normal & normal (ex Pec) \\
\hline CQ162 & $\mathrm{C}$ & $\operatorname{Pr}$ & fused & $?$ & normal & normal (?) & normal \\
\hline CQ167 & $\mathrm{C}$ & $\operatorname{Pr}$ & fused & $?$ & normal & normal (?) & normal \\
\hline CQ203 & $\mathrm{C}$ & $\operatorname{Pr}$ & fused & aligned & normal & normal & normal (ex Pec) \\
\hline CQ208 & $\mathrm{C}$ & $\operatorname{Pr}$ & fused & aligned & $\begin{array}{l}\text { normal } \\
\text { (no LD) }\end{array}$ & ext $\mathrm{Pr} / \mathrm{Dist}$ & normal \\
\hline CQ238 & $\mathrm{C}$ & $\mathrm{Pr}$ & fused & aligned & normal & ext $\mathrm{Pr} / \mathrm{Dist}$ & normal \\
\hline CQ140 & $\mathbf{M}^{\mathrm{m}}$ & Dist & displaced & obl/vent & $\mathrm{D}+\mathrm{Pec}$ Abn & dupl & $\begin{array}{l}\text { present but } \\
\text { malpositioned }\end{array}$ \\
\hline CQ227 & $\mathrm{M}^{\mathrm{m}}$ & Dist & fused & aligned & undiff $D$ to plex & normal & normal (rad depl) \\
\hline CQ228 & $\mathbf{M}^{m}$ & Dist & adjacent & obl/vent & Abn & vent & depl D \\
\hline CQ239 & $\mathbf{M}^{\mathbf{m}}$ & Dist & adjacent & obl/vent & normal & vent/dupl & depl D \\
\hline $\mathrm{CQ} 240$ & $\mathbf{M}^{\mathfrak{c}}$ & $\operatorname{Pr}$ & fused & obl/vent & $\begin{array}{l}\text { Abn/long } \\
\text { shoulder }\end{array}$ & dist & $\begin{array}{l}\text { ext sp nerves, } \\
\text { Abn plex, depl D }\end{array}$ \\
\hline $\mathrm{CQ} 247$ & $\mathbf{M}^{\mathbf{c}}$ & $\operatorname{Pr}$ & fused & vent & $\begin{array}{l}\text { Abn D to plex } \\
\text { \& dist }\end{array}$ & normal & normal (sl red dor) \\
\hline $\mathrm{CQ} 250$ & $\mathbf{M}^{w}$ & $\operatorname{Pr}$ & displaced & vent & normal & vent & normal (sl red dor) \\
\hline $\mathrm{CQ} 256$ & $\mathbf{M}^{\mathrm{m}}$ & $\operatorname{Pr}$ & fused & obl/vent & Abn dist & vent & Abn \\
\hline CQ257 & $\mathbf{M}^{\mathbf{w}}$ & $\operatorname{Pr}$ & displaced & vent & ext shoulder & vent & normal (rad depl) \\
\hline CQ261 & $\mathbf{M}^{m}$ & $\operatorname{Pr}$ & displaced & vent & Abn & vent & Abn \\
\hline CQ306 & $\mathbf{M}^{\mathbf{w}}$ & $\operatorname{Pr}$ & fused & obl/vent & Abn dorsally & dist & Abn \\
\hline CQ310 & $M^{*}$ & Dist & fused & vent & ext shoulder & vent/dupl & normal (rad depl) \\
\hline CQ344 & $\mathrm{M}^{\mathrm{m}}$ & $\operatorname{Pr}$ & displaced & $?$ & Abn shoulder & vent/dist & Abn \\
\hline
\end{tabular}

Individual cases have been subdivided into two major groups, those in which the nerve injected in the rotated limb contained axons from correctly positioned motoneurons (C), and those in which the injected nerve labeled a mixture of correctly positioned and aberrantly positioned motoneurons $(M)$. Information about the level of the graft with respect to the plexus (Level), the degree of fusion of the portion of the wing girdle derived from quail tissue with the chick girdle (Girdle), the position of the grated limb with respect to the host (Limb position), differentiation of tissue within the wing (Limb differentiation), and the location of the wing plexus (Plexus location) is given for each case. See Results for further description.

Abn, abnormal; C, correct; cor ab, coracoid absent; D, dorsal; Dist, distal; depl, depletion; dupl, duplicated; ex Pec, except for pectoralis; ext, extended; LD latissimus dorsi; $\mathbf{M} \cdot$, mixed innervation with the majority of labeled motoneurons in correct positions; $\mathbf{M}^{m}$, mixed innervation with similar numbers of correctly positioned and incorrectly positioned motoneurons; $\mathbf{M}^{*}$, mixed innervation with majority of labeled motoneurons in the wrong position; obl, oblique; Pec, pectoralis; plex, plexus; Pr, proximal; rad, radial nerve; sl red dor, slight reduction dorsally; sp, spinal; undiff, undifferentiated; vent, ventral.

bution of the specific guidance cues governing the D/V pathway choice.

Correcting axonal trajectories in two embryos with appropriately innervated D/V-reversed wings are shown in Figures 4 and 6 . The positions of the retrogradely labeled axons are clearly evident in relation to unlabeled axons in the distal spinal nerves as axons approach and traverse the plexus. In both embryos, it can be seen that proximal to the host-graft border and reversed plexus region, axons of lateral and medial motoncurons are segregated to dorsal and ventral positions, respectively, within the spinal nerves, as they are in embryos with normally oriented wings (e.g., Fig. 1 $A$ ). However, as the labeled axons are traced into reversed quail tissue through the plexus region, many change positions rather abruptly to project to rotated tissue. For example, labcled axons from laterally positioned motoneurons that had segregated to a dorsal position in the spinal nerves corrected their trajectories within the reversed quail plexus to project to the dorsal radial nerve, now located ventrally with respect to the body axes (Fig. $4 C, D$ ). Similarly, axons labeled by the biceps muscle nerve injection were located ventrally in the spinal nerves, but compensated for the reversal within the plexus to project to the now dorsally located biceps muscle (Fig. $6 C, D)$. It should be noted that even though the axons belonged to a single motor pool in this case, individual axons corrected

of the host. $C$, Higher magnification of the plexus region shown in $A$. Note that the dorsally positioned axons in the spinal nerve (curved solid arrow) abruptly correct their trajectories within or at the horder of the rotated quail tissue and within the plexus region (straight solid arrows) and project to the radial nerve now located ventrally with respect to the body axes. Unlabeled axons are marked in the figure with open arrows. $D$, Higher magnification of plexus region in $B$ illustrating the correcting trajectories of a few labeled axons (straight solid arrows) as they traverse the plexus region. Note that the change in trajectory occurs within quail tissue, to the left of the broken lines. Unlabeled axons that have diverged at the plexus to innervate ventral tissue now located dorsally are marked with open arrows. $E$, Eniargement of host-graft border region dorsal to the labeled axons in the spinal nerve shown in $A$ and $C$. Quail cells are identified by the darkly staining clump of heterochromatin in their nuclei. The nuclei of chick cells appear pale in comparison. Note the relative lack of mixing between the two cell populations. $F$, Enlargement of host-graft border region ventral to the spinal nerve shown in $B$ and $D$. The $\mathrm{V}$-shaped structure is a blood vessel. Scale bars: $A$ and $B, 200 \mu \mathrm{m} ; C$ and $D, 50$ $\mu \mathrm{m} ; E$ and $F, 20 \mu \mathrm{m}$. 


\section{A D/N Reversed Dorsal}

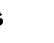
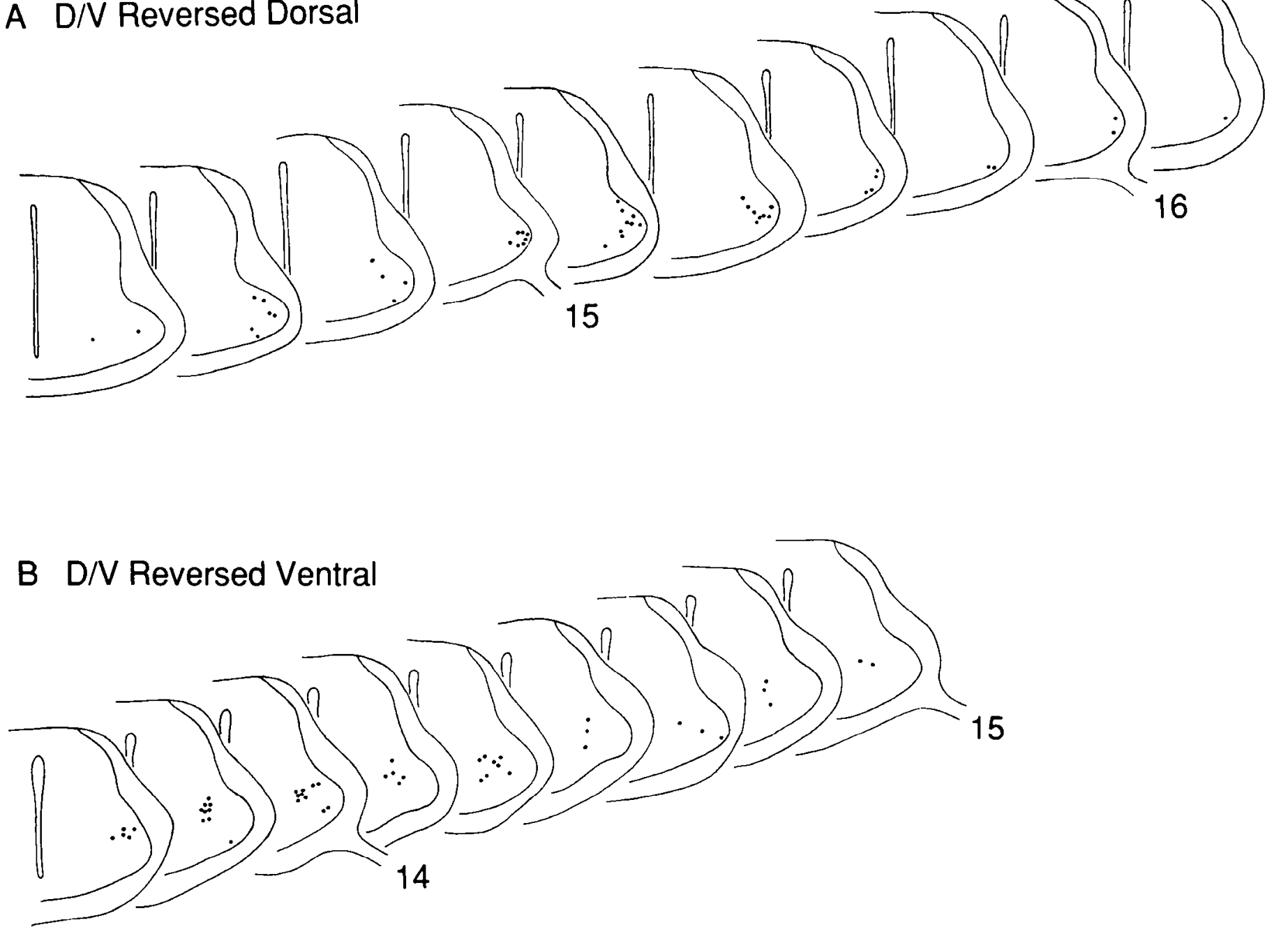

Figure 5. Reconstructions of positions of retrogradely labeled motoneurons following dorsal $(A)$ and ventral $(B)$ nerve injections in experimental chimeras with $\mathrm{D} / \mathrm{V}$-reversed quail wings. $A$, Data for chimera shown in Figure 4 , indicating that the labeled motoneurons were in the appropriate lateral position in the LMC for the dorsal nerve injection (compare with Fig. $2 A$ ). $B$, Data for chimera shown in Figure 6 , in which the nerve to the ventrally derived biceps muscle was injected. The labeled motoneurons were positioned far medially and in segments 14 and 15 , in the normal position of the biceps motor pool (compare with Fig. $2 B$ ). Numbers identify the ventral roots of each spinal cord segment.

their trajectories at differing $P / D$ positions within the plexus region, distributed over a distance of approximately $150 \mu \mathrm{m}$, and not at a single point. As noted above, the level of the wing reversal was found to be critical to the ability of axons to correct. In all D/V-reversed wings with correcting innervation, the level of the host-graft border was proximal to the plexus region; only quail tissue surrounded the plexus.

The correction of axons within the plexus region is also apparent in embryos with $\mathrm{D} / \mathrm{V}$-reversed wings that have been sectioned sagittally. Figure 7 shows a proximal-to-distal series of sections through the plexus region in a chimera in which the radialis nerve trunk was injected. Proximally, where the spinal nerves had just converged and entered quail tissue, the majority of labeled axons had segregated dorsally (Fig. $7 A, B$ ). Slightly more distally, however, they adjusted their position within the quail plexus region to compensate for the $\mathrm{D} / \mathrm{V}$ reversal (Fig. $7 C, D)$, and at the $\mathrm{D} / \mathrm{V}$ pathway divergence projected appropriately to the reversed dorsal musculature (Fig. $7 E, F$ ). In this embryo also, the corrections occurred at a variety of locations within the grafted tissue extending over a $\mathrm{P} / \mathrm{D}$ distance of approximately $150 \mu \mathrm{m}$.

Aberrant innervation patterns. The majority of our experimental chimeras exhibited some degree of aberrant innervation of the rotated limbs. In 13 of the 21 experimental cases, the rotated wings showed varying mixtures of correct and incorrect $\mathrm{D} / \mathrm{V}$ innervation. Totally inappropriate innervation was never observed, however, as has been seen following rotations at more distal levels (Summerbcll and Stirling, 1981; Whitelaw and Hollyday, 1983c; Stirling and Summerbell, 1985). Rather, in our experiments, dorsal or ventral injections resulted in labeled motoneurons in both appropriate and inappropriate positions within the LMC. There was considerable variability among these embryos, both in the relative proportions of correctly versus incorrectly projecting motoneurons, and in the general form of the graft. However, the presence of incorrect innervation was consistently correlated with at least one of two factors, either the $\mathrm{P} / \mathrm{D}$ level of the rotation or abnormal pattern formation in the graft shoulder region (Table 2). 

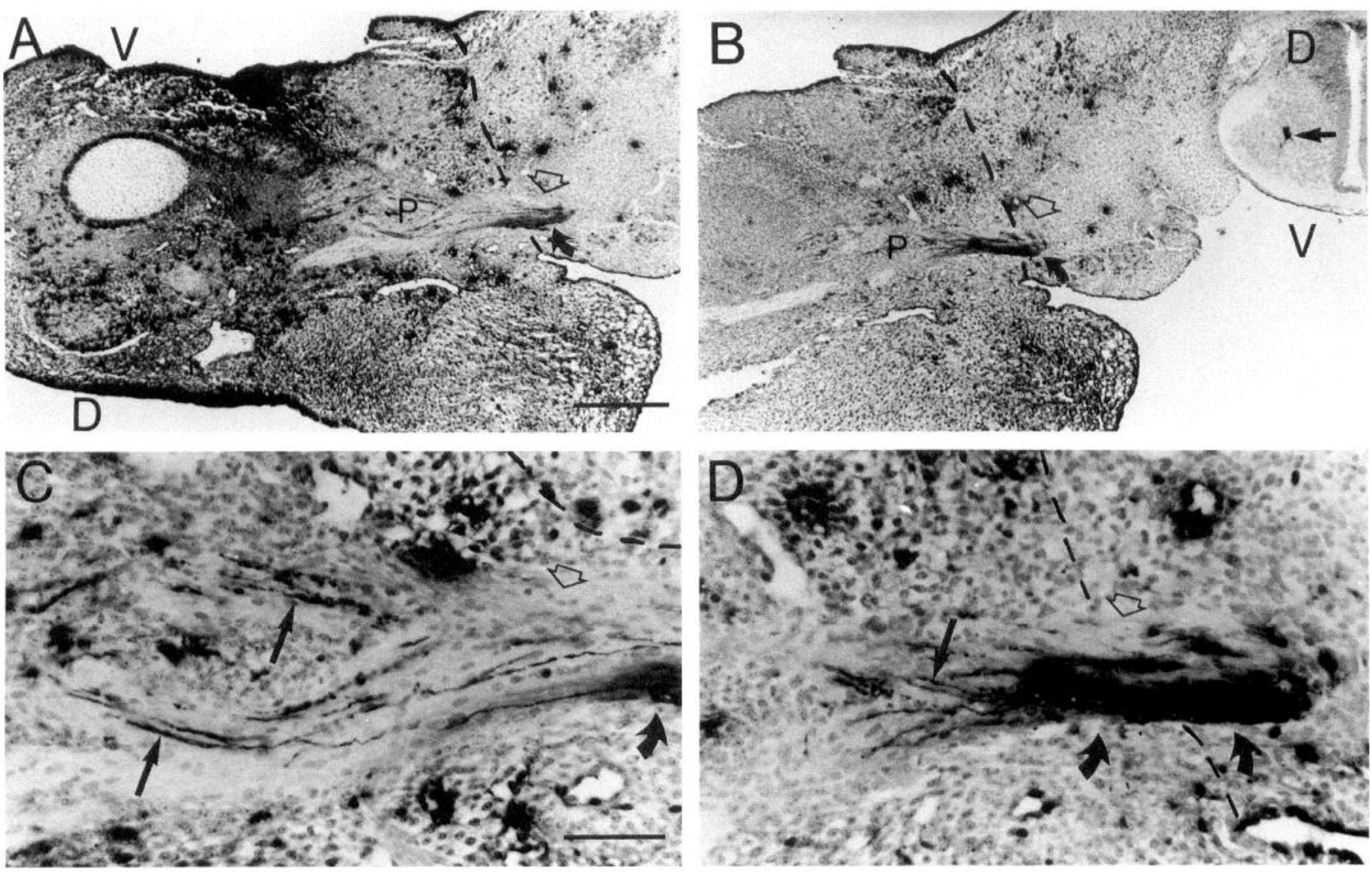

Figure 6. Experimental chimera (stage 29 embryo) with a wing grafted in D/V-reversed orientation (ventral muscle nerve injection). Broken lines mark the border between unrotated chick and rotated quail tissue. $A$, Transverse section near injection site (the biceps muscle nerve). Labeled axons correct their trajectories within the plexus $(P)$ to project to the injected ventral nerve, located dorsally with respect to the body axes (also see $C$ ). Note that the labeled axons (curved solid arrow) have segregated normally to a ventral position in the spinal nerves proximal to the reversal (broken line). In this and subsequent panels, unlabeled axons positioned dorsally in the spinal nerve are marked with an open arrow. $D$ and $V$ denote the reversed orientation of the grafted limb relative to the body axes of the host. $B$, More rostral section showing that motoneurons labeled by the biceps muscle nerve injection were positioned far medially in the LMC (straight solid arrow), in the normal position of the biceps motor pool, with the level of the reversal again lying proximal to the plexus. $D$ and $V$ denote the $\mathrm{D} / \mathrm{V}$ orientation of the body axes of the host. Proximal to the plexus $(P)$ the labeled axons have segregated ventrally (curved solid arrow). $C$, Higher magnification of plexus region in $A$; labeled axons enter the position in a ventral position (curved solid arrow) and correct their trajectories at varying P/D levels within the plexus, and not at a single point (straight solid arrows). $D$, Higher magnification of plexus region in $B$. Correcting axons are marked with a straight arrow. Scale bars: $A$ and $B, 200 \mu \mathrm{m} ; C$ and $D, 50 \mu \mathrm{m}$.

The "mixed" category has been further subdivided into three classes: those in which more than half of the labeled motoneurons were correctly positioned $\left(\mathrm{M}^{\mathrm{c}}\right)$, those in which approximately equal numbers of motoneurons were correctly and incorrectly positioned $\left(\mathrm{M}^{\mathrm{m}}\right)$, and those in which more than half of the labeled motoneurons were aberrantly positioned $\left(\mathrm{M}^{\mathrm{w}}\right)$. No single variable was correlated with aberrant innervation, such as the P/D level of the rotation with respect to the plexus, but some degree of abnormal limb differentiation was evident in all but two of the rotated wings innervated by a mixture of correct and incorrect motoneurons.

Motor axons did not reliably correct if the level of the wing rotation was not entirely proximal to the plexus region. In embryos in which the level of the rotation lay within the plexus, a mixture of correct and incorrect motor innervation was always observed. Some axons typically diverged dorsoventrally within chick tissue and did not subsequently alter their trajectories upon entering quail tissue. Other axons did correct, however, altering their trajectories at a second point of nerve divergence within quail tissue. In a few embryos, the host-graft border formed an oblique angle oriented rostrocaudally through the plexus. This created a situation in which the rostral part of the plexus was formed in unrotated chick tissue and the caudal part was in rotated quail tissue. In these cases, motoneurons positioned rostrally within the motor column did not correct for the rotation; correction was observed only among the population of motoneurons that entered the plexus caudally in the rotated quail tissue (e.g., Fig. 3E). Embryos such as these provide good evidence that axons could correct their $\mathrm{D} / \mathrm{V}$ trajectories only if they encountered rotated tissue proximal to the site of plexus formation.

A far proximal level of rotation was necessary but not sufficient to assure correct innervation of D/V-rotated wings. In 7 out of 13 embryos in which aberrant innervation was observed, the rotations were made entirely proximal to the plexus. Nevertheless, in these cases, innervation of the rotated wings consisted of a mixture of correct and incorrect motoneurons (Fig. $3 F$ ). Irrespective of the $\mathrm{P} / \mathrm{D}$ level of rotation, if abnormal dif- 

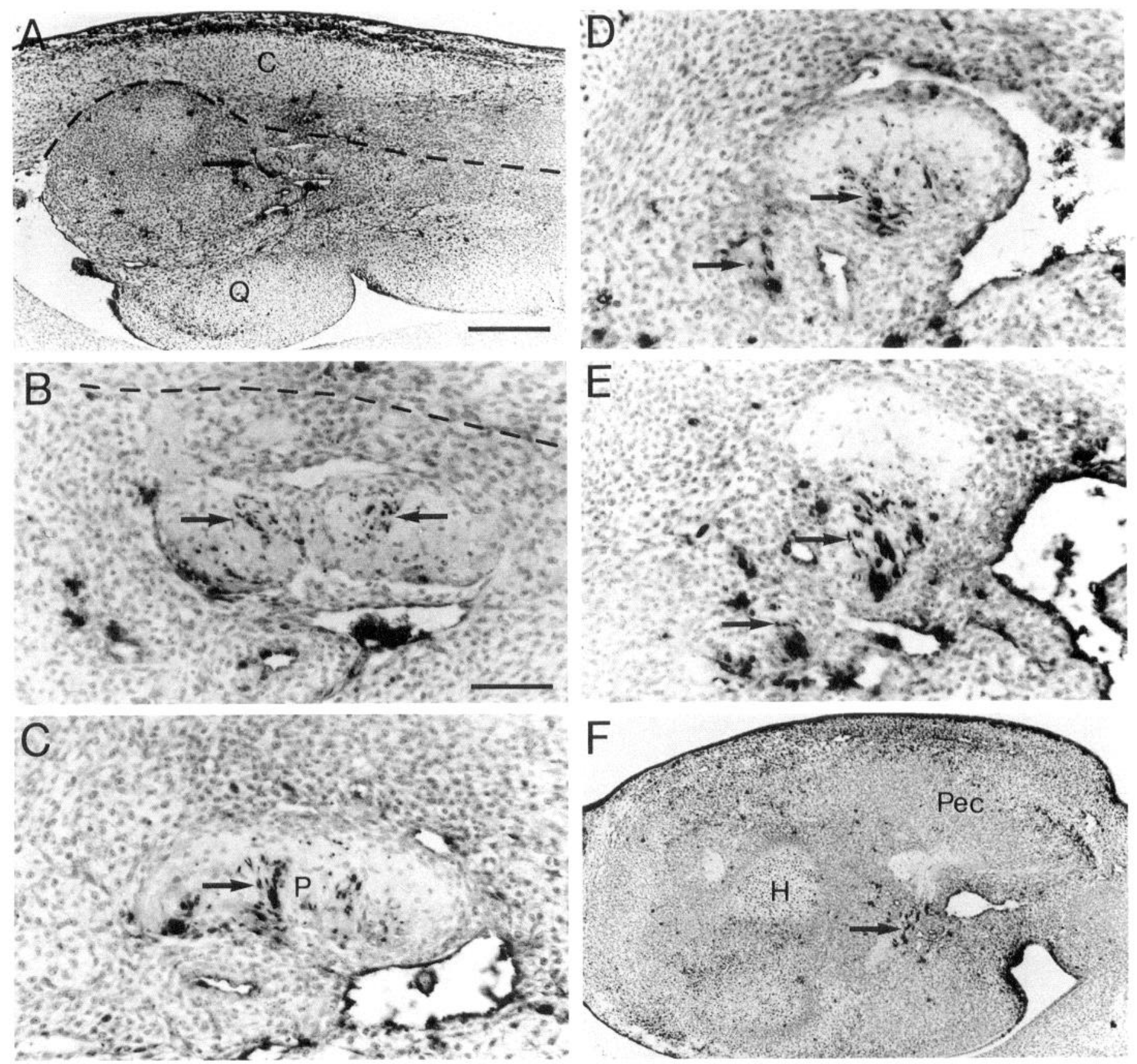

Figure 7. Experimental chimera (stage 28) with a D/V-reversed wing and a dorsal nerve trunk injection (sagittal sections): proximal-to-distal series of sections through the plexus region. Broken lines in $A$ and $B$ show border between host and graft tissue. Dorsal is to the top. $A$, Section just proximal to the plexus where the spinal nerves have just converged (arrow) and extended from chick $(C)$ into quail $(Q)$ tissue. $B$, Higher magnification of spinal nerves in $A$. The majority of labeled axons have segregated normally to a dorsal position proximal to the plexus (arrows). $C$, Section $64 \mu \mathrm{m}$ distal to $A$ and $B$. Many labeled axons are positioned ventrally to where they were in $B$, presumably correcting their trajectories (arrow) within the $\mathrm{D} / \mathrm{V}$-reversed quail plexus region $(P)$ in response to the experimental rotation. $D$, Section $64 \mu \mathrm{m}$ distal to $C$. The majority of labeled axons (arrows) are positioned ventrally and have adjusted their positions within the plexus to compensate for the rotation. $E$, Section 64 $\mu \mathrm{m}$ distal to $D$. At the separation of the dorsal and ventral pathways, the labeled axons diverge to project to dorsally derived musculature. $F$, Section $64 \mu \mathrm{m}$ distal to $E$, showing low-magnification view (as in $A$ ) of the $\mathrm{D} / \mathrm{V}$-reversed quail wing. Labeled axons can be seen projecting into the brachialis superior nerve trunk as it diverges around the head of the humerus $(H)$. The ventrally derived pectoralis muscle $(P e c)$ can be seen positioned dorsally with respect to the body axes. Scale bars: $A$ and $F, 200 \mu \mathrm{m} ; B-E, 50 \mu \mathrm{m}$.

ferentiation and pattern formation occurred, the wings were innervated abnormally.

Abnormal limb pattern formation took many forms, involving either incomplete or abnormal differentiation of the limb tissue, especially adjacent to the donor scapula and the plexus region, and distally within the muscle masses of the developing forewing (Table 2). In some embryos, the cells in these regions were loosely organized and appeared to be undifferentiated mesenchyme. In others, the host and graft girdle elements were differentiated but misaligned and unfused, resulting in abnor- 
mally long shoulder regions. Disturbed limb pattern formation was often associated with a slight misalignment of the graft with the host.

Disturbances of limb pattern formation in the host-graft border region were always associated with abnormalities in the plexus location or pattern, and in the pattern of nerve branching distal to the plexus. This was particularly evident in cases in which the graft appeared to have been positioned too far ventrally on the host, resulting in an abnormal point of spinal nerve entry into the limb. Abnormal plexus location or peripheral nerve branching pattern was invariably correlated with some degree of incorrect innervation of the rotated wing. If limb pattern formation was disrupted sufficiently, the wings failed to be innervated, and the embryos were not included in this study.

\section{Discussion}

\section{Specificity of $D / V$ innervation}

The axonal guidance mechanisms involved in the specific $D / V$ pathway choice for motoncurons during limb innervation were examined by making limb bud transplantations in chick/quail chimeras. Control experiments in which quail wings were grafted in normal orientation established that chick motoncurons were able to respond, presumably selectively, to guidance cues in the quail limb, and to project appropriately to either dorsal or ventral musculature. In a similar study of chick/quail chimeras, but in the hindlimb, Tanaka and Landmesser (1986) further reported that individual chick (or quail) motoneuron pools selectively innervated homologous muscles in the opposite species. It therefore appears that the guidance mechanisms and cues are very similar, if not identical, in the two species, and that grafting of quail wing buds in $\mathrm{D} / \mathrm{V}$-reversed orientation can provide a test of whether active or passive guidance mechanisms govern the specific pattern of $D / V$ projection at the plexus.

In reversed grafts, despite the reversal of their target, under certain conditions motoneurons were able to compensate and project appropriately for their position in the transverse plane of the LMC. Although only a proportion of all of the axons in the injected nerve trunks werc labeled in our experiments, there is no reason to believe that they formed an unrepresentative sample of the population of axons in the nerve. In general, fewer motoneurons were labeled overall in experimental embryos than in controls. We attribute these differences to two factors. First, we selected only the most heavily labeled controls for quantitative analysis, while all experimental embryos with specific injections and evidence of successful retrograde transport were analyzed quantitatively. Second, we think that motor axons find it difficult to alter their growth trajectories to compensate for the $\mathrm{D} / \mathrm{V}$ reversal because of imperfect tissue differentiation and pattern formation in the reversed plexus region (see below), and that some axons simply fail to grow through the reversed plexus into the limb. This interpretation also consistent with the general conclusion made previously by ourselves and others that more than one guidance mechanism is normally employed by axons to assure accurate axonal navigation.

The positions of labeled motoneurons within the LMC are presumably a reliable index of the degree of correct innervation of the experimentally reversed limb, and the percentages of correct and incorrectly positioned cells are similar in the controls and the best-correcting cases. As the specificity of innervation was assessed prior to the period of motoneuron death, com- pensation for the reversal occurred during initial axon outgrowth, rather than by selective elimination of inappropriate $\mathrm{D} / \mathrm{V}$ projections. The outgrowing axons of laterally and medially positioned motoneurons clearly responded selectively to specific $\mathrm{D} / \mathrm{V}$ guidance cues associated with the reversed quail limb. Active axonal guidance mechanisms must therefore be involved in the specific $\mathrm{D} / \mathrm{V}$ pathway choice.

This conclusion is consistent with a number of previous studies indicating that motoneurons are of differing identity, and are specified prior to outgrowth for particular target regions. Specificity of projections based upon motor pool position rostrocaudally within the LMC has also been demonstrated following experimental manipulations involving both the A/P (LanceJones and Landmesser, 1980; Stirling and Summerbell, 1983, 1985) and P/D (Whitelaw and Hollyday, 1983a) axes of the limb. In particular, following small $\mathrm{A} / \mathrm{P}$ spinal cord reversals (Lance-Jones and Landmesser, 1980), and A/P limb reversals (Stirling and Summerbell, 1983, 1985), motoneurons were found to innervate selectively their appropriate (or original) targets during initial outgrowth, prior to motoneuron death. Compensation for these reversals by the outgrowing axons indicates that active axonal responses to specific cues are involved in pathway selection on the $\mathrm{A} / \mathrm{P}$ axis also.

As noted in the introductory remarks, previous investigations of the guidance mechanisms involved in the specific projections on the $\mathrm{D} / \mathrm{V}$ axis have produced conflicting results. Ferguson (1983) and Laing (1984) found evidence for active guidance, reporting appropriate innervation of $\mathrm{D} / \mathrm{V}$-reversed hindlimbs and $\mathrm{D} / \mathrm{V}$ - and $\mathrm{A} / \mathrm{P}$-reversed wings, respectively. In contrast, Summerbell and Stirling (1981; Stirling and Summerbell, 1983, 1985) found no selectivity in the motor projections to reversed wings, and suggested passive deployment on the $D / V$ axis. $D / V$ rotations at more distal limb levels have been shown to result consistently in incorrect innervation of the reversed segments (Summerbell and Stirling, 1981; Whitelaw and Hollyday, 1983c). Axons appear to become constrained by their choice at the plexus to either dorsal or ventral pathways, and to become largely unable to alter their course distally to compensate for a $\mathrm{D} / \mathrm{V}$ rotation. It seems possible, therefore, that the conflicting results of the previous $\mathrm{D} / \mathrm{V}$ limb reversal studies may relate to differences in the P/D levels of the rotations, which were essentially unknown.

Using chick/quail chimeras, we have directly examined whether the level of the reversal is corrclated with the specificity of innervation. Correct $D / V$ innervation of the reversed wings was found to be dependent on the level of the graft being fully proximal to the quail plexus region. Conversely, some level of inappropriate innervation resulted from slightly more distal reversals that lay within the plexus; in these embryos axons had begun to diverge while still within chick tissue. These axons generally failed to correct upon encountering the reversed quail tissue. Our results, therefore, indicate that the ability to correct for a $D / V$ reversal is dependent on the $P / D$ level of the rotation in relation to the plexus. One reason for axons failing to correct may be that they did not enter the graft in the normal plexus region, and were therefore distant from the normal $D / V$ cues. Alternatively, once having diverged to either dorsal or ventral pathways, they may have become committed by general pathway constraints, with no longer any opportunity to correct their path of outgrowth (Whitelaw and Hollyday, 1983c). Axons, therefore, seemingly respond within the reversed plexus region to specific $\mathrm{D} / \mathrm{V}$ guidance cues in order to correct. Further in- 
formation on the nature and distribution of these cues is given by the correcting axon trajectories.

\section{Axon trajectories}

The pattern of axon trajectories in chimeras with unrotated grafted wings was similar to that in normal chick wings (M. J. Ferns, unpublished observations). Although the axons of lateral and medial motoneurons exited the spinal cord relatively mixed in the ventral roots, they segregated to dorsal and ventral positions within the spinal nerves, proximal to the plexus. Similar observations have been made for normal chick hindlimb (LanceJones and Landmesser, 1981a; Ferguson, 1983), and in experimental embryos with a double complement of dorsally derived muscles and no ventrally derived ones (Lance-Jones, 1986).

This pattern was also preserved in chimeras with D/V-reversed wings, with axons segregating normally within the spinal nerves, proximal to the rotation, according to their lateral or medial origin. However, upon encountering the graft, axons abruptly altered their trajectories to compensate for the $D / V$ reversal. This occurred within, or at the border of the rotated quail tissue, and in the plexus region. These abrupt changes in the relative positions of individual axons cannot be readily explained by morphogenetic tissue movements accompanying limb growth, which would affect the entire population of axons, but are interpreted as reflecting the active responses of axons to specific cues during their initial outgrowth.

Correction by axons was not seen until axons entered the reversed tissue. Also, mixtures of appropriate and inappropriate innervation were seen in some rotated wings, with only a proportion of axons correcting their path of outgrowth. Both of these observations suggest the specific $D / V$ guidance cues are unlikely to be long-range, target-derived signals, but are instead localized and associated with the environment through which the axons grow as they approach and traverse the plexus (Tosney and Landmesser, 1984; Phelan and Hollyday, 1990). LanceJones (1986) also concluded that the cues governing the initial sorting on the $\mathrm{D} / \mathrm{V}$ axis are independent of the limb proper, because she observed a consistent pattern of inappropriate innervation of surgically created limbs having a double complement of dorsally derived target muscles. In those experiments, she found that donor-derived dorsal muscles positioned ventrally within the limb were consistently innervated by motor pools that normally supply ventral muscles.

Axons corrected their relative $\mathrm{D} / \mathrm{V}$ position within the rotated plexus region to project appropriately at the divergence of the dorsal and ventral nerves, as was also described following $\mathrm{D} / \mathrm{V}$ rotations of the chick hindlimb (Ferguson, 1983). Within individual cases, correcting trajectories were frequently distributed at varying levels proximodistally within the plexus region, and were not necessarily localized to a single point. This was particularly noteworthy in the case involving the biceps muscle nerve injection, where axons from a single motor pool corrected over a P/D distance of at least $150 \mu \mathrm{m}$. This suggests, therefore, that the cues that direct axons to either dorsal or ventral pathways are relatively distributed within the plexus region.

It was not possible to perform $D / V$ reversals significantly proximal to the plexus region, in order to test whether correction could also occur in the spinal nerves. However, as axons of lateral and medial motoneurons were seen to sort out dorsoventrally within the spinal nerves proximal to the plexus, specific $\mathrm{D} / \mathrm{V}$ guidance cues may also be distributed more proximally. This interpretation is consistent with our findings that growth cones are enlarged in the distal spinal nerves as they approach the plexus region, as they are within the plexus region itself (M. Hollyday, unpublished observations).

The apparent distributed nature of the specific $\mathrm{D} / \mathrm{V}$ guidance cues is in contrast to the findings in the PNS of invertebrates. In insect embryos, specific guidance cues for pioneering axons are localized to individual guidepost neuron or glial cells (Bentley and Keshishian, 1982; Ho and Goodman, 1982; Taghert et al., 1982; Bentley and Caudy, 1983; Keshishian and Bentley, 1983a), and for later projections, to preformed axonal pathways (Ho and Goodman, 1982; Keshishian and Bentley, 1983b). Such specific cues may exist, however, on a background of gencral gradients conferring polarity information (Nardi and Kafatos, 1976a,b; Nardi, 1983; Berlot and Goodman, 1984; Caudy and Bentley, 1986).

\section{$D / V$ guidance and positional information}

The ability of axons to correct and project appropriately to D/Vreversed wings depended on the level of the graft being proximal to the plexus. A far proximal level of rotation was necessary but not sufficient to assure correct innervation of D/V-rotated wings. Aberrant innervation patterns consisting of mixtures of correct and incorrect innervation were observed in some embryos with far proximal reversals. A characteristic feature of these embryos was an abnormal pattern of tissue differentiation in the graft shoulder region. Therefore, an additional requirement for correcting innervation was the development of normal limb pattern in the rotated graft.

Pattern formation in the developing limb bud is thought to be based on a system of positional information (see Wolpert, 1989 , for a review). We think it noteworthy that nearly all of the chimeric limbs grafted in normal orientation differentiated normally, even if they were misaligned along the $A / P$ axis, whereas the majority of the grafts made at the same times, but in $\mathrm{D} / \mathrm{V}$-reversed orientation, showed signs of abnormal differcntiation. It thus seems reasonable to suggest that the disturbed pattern at the host-graft border arises from conflicting $D / V$ positional information signals from the apposed but reversed chick and quail tissue, and the failure of the border cells to resolve the conflict in order to differentiate and form a pattern.

There was a close corrclation between active correction by the outgrowing axons and development of normal limb pattern in the reversed wing, raising the possibility that they are determined, at least in part, by common processes. We think it noteworthy that disturbances of limb pattern formation in the hostgraft border region were always associated with abnormalities of nerve pattern formation, and that there was a close positive correlation between the degree of pattern abnormality at the host-graft border, with abnormal plexus and distal nerve pattern formation, and the degree of incorrect innervation of the rotated wing. This leads us to suggest that axons normally respond, in a specific fashion, directly to the positional information signal encoding the $\mathrm{D} / \mathrm{V}$ axis of the developing limb bud, or indirectly to cues that differentiate in the plexus region in accord with $D / V$ positional value. In the event of abnormal $\mathrm{D} / \mathrm{V}$ pattern formation at the plexus region prior to or at the time of initial innervation, axons project aberrantly into the limb bud, forming abnormal gross nerve patterns and inappropriate motor innervation.

A similar proposal has been made by Stirling and Summerbell (1988), from studies of axon guidance in limbs that were partially duplicated about the A/P axis by the grafting of an ad- 
ditional zone of polarizing activity (ZPA). Axons were observed to change $A / P$ position within the radial nerve to innervate specifically both the normal and the anteriorly duplicated (posterior) extensor metacarpi ulnaris muscle. Axons altered their trajectories proximal to the overt level of duplication of limb pattern. Stirling and Summerbell concluded that the axons responded selectively, either directly to the $A / P$ signal from the grafted ZPA, or indirectly to changes in cellular positional value specified by the ZPA, rather than to a new pattern of local differentiation.

Active axonal guidance mechanisms have been directly implicated in the specific motor projections on both the A/P (LanceJones and Landmesser, 1980, 1981 b; Stirling and Summerbell, 1985 ) and D/V (Ferguson, 1983; Laing, 1984; present study) axes of the developing limb. While nonspecific growth cues may be distributed, the specific guidance cues to which the axons selectively respond are generally thought to be localized to "choice points" in axon outgrowth, or pathway decision regions. Such a scheme has been well demonstrated for axon guidance in the invertebrate CNS (reviewed in Bastiani et al., 1985).

Several observations, however, prompt us to reevaluate this model for the vertebrate limb. At early stages of limb innervation, the axonal projections occupy a large volume, relative to the size of the limb, and defined pathways with discrete branch points only emerge later, as a secondary consequence of other processes (e.g., limb growth, axonal bundling by glia). Therefore, guidance cues, such as those associated with the D/V pathway choice, would be required to be relatively widespread. Because we observed axons segregating into appropriate dorsal and ventral positions within the spinal nerves, and then abruptly changing positions within the plexus region, we think that the $\mathrm{D} / \mathrm{V}$ guidance cues are distributed in the plexus region and also more proximally. Similarly, the guidance cues associated with the A/P axis appear to be widespread and not confined to just the plexus or to more distal branch points (Stirling and Summerbell, 1985, 1988). Further, guidance cues might be related to the specification of positional information and pattern formation because normal differentiation of the shoulder region was essential to correction. We suggest, therefore, that the specific axonal guidance cues may not be strictly pathway associated and localized to critical choice points, but may in some instances exist as generalized gradients of positional information defining the $\mathrm{D} / \mathrm{V}$ and $\mathrm{A} / \mathrm{P}$ axes.

\section{References}

Bastiani MJ, Doe CQ, Helfand SL, Goodman CS (1985) Neuronal specificity and growth cone guidance in grasshopper and Drosophila embryos. Trends Neurosci 8:257-266.

Bentley D, Caudy M (1983) Pioneer axons lose directed growth after selective killing of guidepost cells. Nature 304:62-65.

Bentley D, Keshishian H (1982) Pathfinding by peripheral pioneer neurons in the grasshopper. Science 218:1082-1088.

Berlot J, Goodman CS (1984) Guidance of peripheral pioneer neurons in the grasshopper: adhesive hierarchy of epithelial and neuronal surfaces. Science 223:493-496.

Caudy M, Bentley D (1986) Pioneer growth cone morphologies reveal proximal increases in substrate affinity within leg segments of grasshopper embryos. J Neurosci 6:364-379.

Ferguson BA (1983) Development of motor innervation of the chick following dorsal-ventral limb bud rotations. J Neurosci 3:1760-1 772.

Ferns MJ, Hollyday M (1989) Motor innervation of dorsoventrally reversed wings in chick/quail chimaeric embryos. Soc Neurosci Abstr 15:1028.
Hamburger V, Hamilton $H$ (1951) A series of normal stages in the development of the chick embryo. J Morphol 88:49-92.

Ho RK, Goodman CS (1982) Peripheral pathways are pioneered by an array of central and peripheral neurones in grasshopper embryos. Nature 297:404-406.

Hollyday M (1980) Organization of motor pools in chick lumbar lateral motor column. J Comp Neurol 194:143-170.

Hollyday M (1981) Rules of motor innervation in chick embryos with supernumerary limbs. J Comp Neurol 202:439-465.

Hollyday M (1983) Development of motor innervation of chick limbs. In: Limb development and regeneration (Fallon JF, Caplan AI, eds), pp 183-193. New York: Liss.

Hollyday M, Jacobson RD (1990) Location of motor pools innervating chick wing muscles. J Comp Neurol 302:575-588.

Jacob M. Christ B. Jacob HJ (1978) On the migration of myogenic stem cells into the prospective wing region of chick embryos: a scanning and transmission electron microscope study. Anat Embryol (Berl) 153:179-193.

Keshishian H, Bentley D (1983a) Embryogenesis of peripheral nerve pathways in grasshopper legs. I. The initial nerve pathway to the CNS. Dev Biol 96:89-102.

Keshishian H, Bentley D (1983b) Embryogenesis of peripheral nerve pathways in grasshopper legs. II. The major nerve routes. Dev Biol 96:103-115.

Laing NG (1984) Motor innervation of proximally rotated chick embryo wings. J Embryol Exp Morphol 83:213-223.

Lance-Jones CC (1986) Motoneuron projection patterns in chick embryonic limbs with a double complement of dorsal thigh musculature. Dev Biol 116:387-406.

Lance-Jones C, Landmesser LT (1980) Motoneurone projection patterns in the chick hind limb following early partial reversals of the spinal cord. J Physiol (Lond) 302:581-602.

Lance-Jones C, Landmesser LT (1981a) Pathway selection by chick lumbosacral motoneurons during normal development. Proc R Soc Lond [Biol] 214:1-18.

Lance-Jones C, Landmesser LT (1981b) Pathway selection by embryonic chick motoneurons in an experimentally altered environment. Proc R Soc Lond [Biol] 214:19-52.

Landmesser LT (1978a) The distribution of motoneurons supplying the chick hindlimb muscles. J Physiol (Lond) 284:371-390.

Landmesser LT (1978b) The development of motor projection patterns in the chick hindlimb. J Physiol (Lond) 284:391-414.

Le Douarin N (1973) A biological cell labelling technique and its use in experimental embryology. Dev Biol 30:217-222.

Morris DG (1978) Development of functional motor innervation in supernumerary hindlimbs of the chick embryo. J Neurophysiol 41: $1450-1465$

Nardi JB (1983) Neuronal pathfinding in developing wings of the moth Manduca sexta. Dev Biol 95:163-174.

Nardi JB, Kafatos FC (1976a) Polarity and gradients in lepidopteran wing epidermis. I. Changes in graft polarity, form, and cell density, accompanying transpositions and reorientations. J Embryol Exp Morphol 36:469-487.

Nardi JB, Kafatos FC (1976b) Polarity and gradients in lepidopteran wing epidermis. II. The differential adhesiveness model: gradient of a non-diffusible cell surface parameter. J Embryol Exp Morphol 36: $489-512$

Ohmori Y, Watanabe T, Fujioka T (1982) Localization of the motoneurons innervating the forelimb muscles in the spinal cord of the domestic fowl. Zentralbl Veterinaermed [C] 11:124-137.

Oppenheim RW, Majors-Willard C (1978) Neuronal cell death in the brachial spinal cord of the chick is unrelated to the loss of polyneuronal innervation in wing muscle. Brain Res 154:148-152.

Phelan KA, Hollyday M (1990) Axon guidance in muscleless chick wings: the role of muscle cells in motoneuronal pathway selection and muscle nerve formation. J Neurosci 10:2699-2716.

Sternberger LA (1979) The unlabelled antibody peroxidase anti-peroxidase (PAP) method. In: Immunocytochemistry, pp 104-169. Englewood Cliffs, NJ: Prentice-Hall.

Stirling RV, Summerbell D (1983) Familiarity breeds contempt: the behaviour of axons in foreign and familiar environments. In: Limb development and regeneration, Pt A (Fallon JF, Caplan AI, eds), pp 217-226. New York: Liss.

Stirling RV, Summerbell D (1985) The behaviour of growing axons 
invading developing chick wing buds with dorsoventral or anteroposterior axis reversed. J Embryol Exp Morphol 85:251-269.

Stirling RV, Summerbell D (1988) Specific guidance of motor axons to duplicated muscles in the developing amniote limb. Development 103:97-110.

Straznicky C (1983) The patterns of innervation and movements of ectopic hindlimb supplied by brachial spinal cord segments in the chick. Anat Embryol (Berl) 167:247-262.

Straznicky C, Tay C (1983) The localization of motoneuron pools innervating wing muscles in the chick. Anat Embryol (Berl) 166:209218.

Summerbell D, Stirling RV (1981) The innervation of dorsov ${ }^{-\cdots}$ rally reversed chick wings: evidence that motor axons do not activery seek out their appropriate targets. J Embryol Exp Morphol 61:233-247.

Taghert PH, Bastiani MJ, Ho RK, Goodman CS (1982) Guidance of growth cones: filopodial contacts and coupling revealed with an antibody to Lucifer yellow. Dev Biol 94:391-399.
Tanaka H, Landmesser LT (1986) Interspecies selective motoneuron projection patterns in chick-quail chimeras. J Neurosci 6:2880-2888.

Tosney KW, Landmesser LT (1984) Pattern and specificity of axonal outgrowth following varying degrees of chick limb bud ablation. J Neurosci 4:2518-2527.

Whitelaw V, Hollyday M (1983a) Thigh and calf discrimination in the motor innervation of the chick hindlimb following deletions of limb segments. J Neurosci 3:1199-1215.

Whitelaw V, Hollyday M (1983b) Position-dependent motor innervation of the chick hindlimb following serial and parallel duplications of limb segments. J Neurosci 3:1216-1225.

Whitelaw V, Hollyday M (1983c) Neural pathway constraints in the motor innervation of the chick hindlimb following dorsoventral rotations of distal limb segments. J Neurosci 3:1226-1233.

Wolpert L (1989) Positional information revisited. Development [Suppl] 107:3-12. 